\title{
Prioritized List of Research Needs to support MRWFD Case Study Flowsheet Advancement
}

Fuel Cycle Technology

Prepared for U.S. Department of Energy Materials Recovery and Waste Form Development Campaign J. Law, T. Todd, N. Soelberg (INL), C. Pereira, M. Williamson, W. Ebert, J. Willit (ANL), R. Jubin, (ORNL), J. Vienna, G. Lumetta, (PNNL), T. Rudisill (SRNL)

Idaho National Laboratory June 17, 2015 FCRD-MRWFD-2015-000571 



\section{DISCLAIMER}

This information was prepared as an account of work sponsored by an agency of the U.S. Government. Neither the U.S. Government nor any agency thereof, nor any of their employees, makes any warranty, expressed or implied, or assumes any legal liability or responsibility for the accuracy, completeness, or usefulness, of any information, apparatus, product, or process disclosed, or represents that its use would not infringe privately owned rights. References herein to any specific commercial product, process, or service by trade name, trade mark, manufacturer, or otherwise, does not necessarily constitute or imply its endorsement, recommendation, or favoring by the U.S. Government or any agency thereof. The views and opinions of authors expressed herein do not necessarily state or reflect those of the U.S. Government or any agency thereof. 



\section{SUMMARY}

In FY-13, a case study evaluation was performed of full recycle technologies for both the processing of light-water reactor (LWR) used nuclear fuels as well as fast reactor (FR) fuel in the full recycle option. This effort focused on the identification of the case study processes and the initial preparation of material balance flowsheets for the identified technologies. In identifying the case study flowsheets, it was decided that two cases would be developed: one which identifies the flowsheet as currently developed and another near-term target flowsheet which identifies the flowsheet as envisioned within two years, pending the results of ongoing research.

The case study focus is on homogeneous aqueous recycle of the U/TRU resulting from the processing of LWR fuel as feed for metal fuel fabrication. The metal fuel is utilized in a sodium cooled fast reactor and the used fast reactor fuel processed using electrochemical separations. The recovered U/TRU from electrochemical separations is recycled to fuel fabrication and the fast reactor. Waste streams from the aqueous and electrochemical processing are treated and prepared for disposition. Off-gas from the separations and waste processing are also treated.

As part of the FY-13 effort, preliminary process unknowns and research needs to advance the near-term target flowsheets were identified. In FY-14, these research needs were updated, expanded and prioritized. This report again updates the prioritized list of research needs based upon results to date in FY-15. The research needs are listed for each of the main portions of the flowsheet: 1) Aqueous headend, 2) Headend tritium pretreatment off-gas, 3) Aqueous U/Pu/ $\mathrm{Np}$ recovery, 4) Aqueous TRU product solidification, 5) Aqueous

actinide/lanthanide separation, 6) Aqueous off-gas treatment, 7) Aqueous HLW management, 8) Treatment of aqueous process wastes, 9) E-chem actinide separations, 10) E-chem off-gas, 11) E-chem HLW management. The identified research needs were prioritized within each of these areas. No effort was made to perform an overall prioritization. This information will be used by the MRWFD Campaign leadership in research planning for FY-16. Additionally, this information will be incorporated into the next version of the Case Study Report scheduled to be issued September 2015. 
Prioritized List of Research Needs to support MRWFD Case Study Flowsheet Advancement 


\section{CONTENTS}

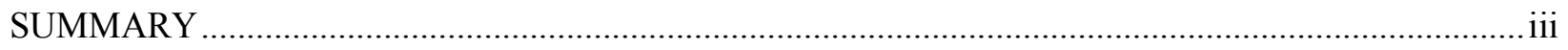

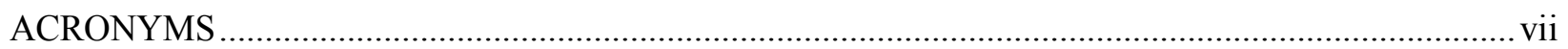

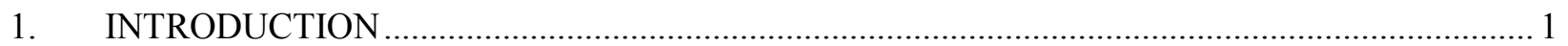

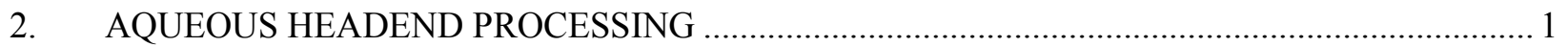

3. HEADEND TRITIUM PRETREATMENT OFF-GAS ........................................................... 2

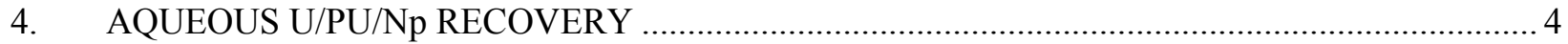

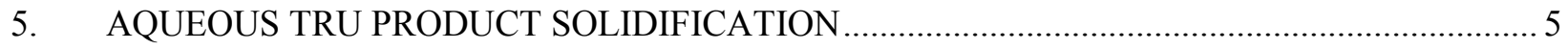

6. AQUEOUS ACTINIDE-LANTHANIDE SEPARATION ....................................................... 5

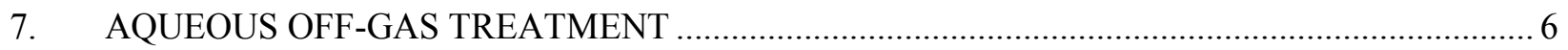

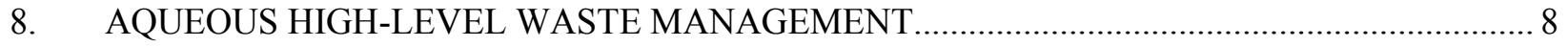

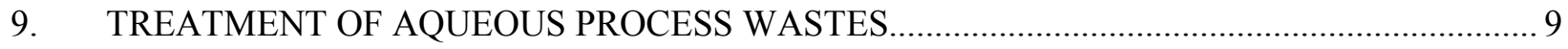

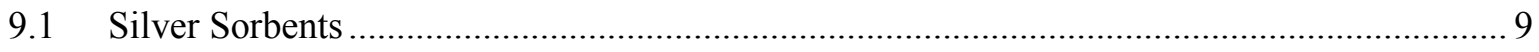

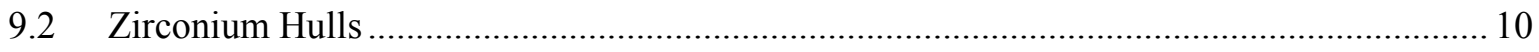

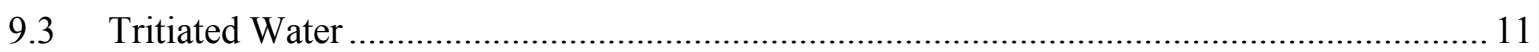

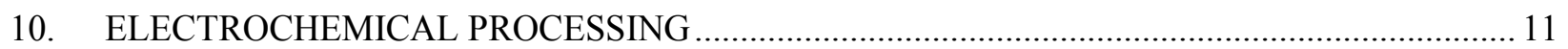

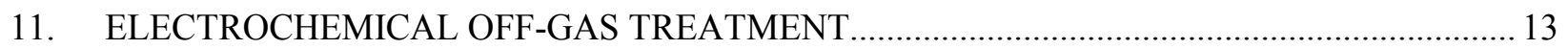

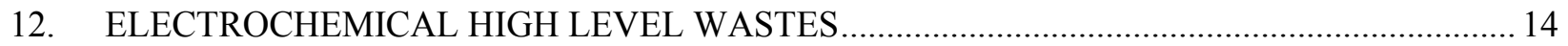

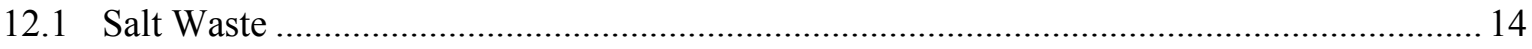

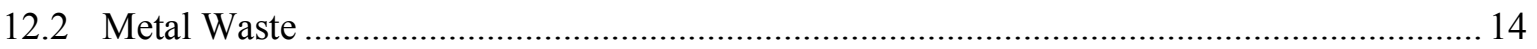

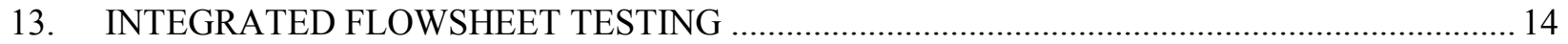

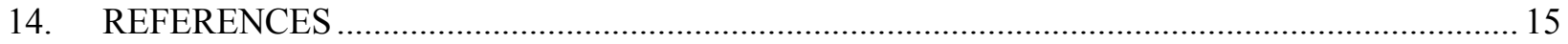


Prioritized List of Research Needs to support MRWFD Case Study Flowsheet Advancement 


\section{ACRONYMS}

3AMS

$\mathrm{AgZ}$

AHA

AMUSE

CECE

CETE

CWF

DOG

DTPA

DyAMUSE

E-chem

FR

GCM

HDEHP

HEH[EHP]

HFIR

HIP

HLW

HUP

ILW

LEU

LWR

MDD

MOF

$\mathrm{MOx}$

MRWFD

ORNL

PUREX

R\&D

TALSPEAK

TBP

TRU

TRUEX

UDS

UNF

VOG
3A Molecular Sieve

Silver zeolite

Acetohydroxamic Acid

Argonne Model for Universal Solvent Extraction

Combined Electrolysis Catalytic Exchange

Coupled End-to-End Demonstration

Ceramic Waste Form

Dissolver Off-Gas

Diethylene Triamine Pentaacetic Acid

Dynamic Argonne Model for Universal Solvent Extraction

Electrochemical Processing

Fast Reactor

Glass Composite Material

Bis-(2-Ethylhexyl) Phosphoric Acid

2-ethylhexylphosphonic acid mono-2-ethylhexyl ester

High-Flux Isotope Reactor

Hot Isostatic Press

High-Level Waste

Hot Uniaxially Pressed

Intermediate-Level Waste

Low Enriched Uranium

Light Water Reactor

Modified Direct Denitration

Metal Organic Framework

Mixed Oxide Fuel

Material Recovery and Waste Form Development

Oak Ridge National Laboratory

Plutonium Uranium Reduction Extraction

Research and Development

Trivalent Actinide Lanthanide Separations by Phosphorus Agent Extraction from Aqueous Komplexes

Tri-Butyl Phosphate

Transuranic

Transuranic Extraction Process

Undissolved Solids

Used Nuclear Fuel

Vessel Off-Gas 
Prioritized List of Research Needs to support MRWFD Case Study Flowsheet Advancement 


\section{PRIORITIZED LIST OF RESEARCH NEEDS TO SUPPORT MRWFD CASE STUDY FLOWSHEET ADVANCEMENT}

\section{INTRODUCTION}

In FY-13 and FY-14, a case study evaluation was performed of full recycle technologies for both the processing of light-water reactor (LWR) used nuclear fuel (UNF) as well as fast reactor (FR) UNF in the full recycle option. (Law et al. 2103 and 2014)This effort focused on the identification of the case study flowsheet which represents the consensus of where we are today with regards to an advanced flowsheet for the recycle of UNF. In addition, this evaluation included the initial preparation of material balance flowsheets for the identified technologies. In identifying the case study flowsheets, it was decided that two cases would be developed: the case-study identifies the flowsheet with the most mature available processes that will meet program goals currently developed and the near-term target flowsheet which identifies the flowsheet with distinct advantages over the case study flowsheet and is of sufficient technical maturity to provide confidence of successful implementation after completing sufficient additional on-going programmatic research as envisioned within approximately two years. The case study focus is on homogeneous aqueous recycle of the U/TRU resulting from the processing of LWR UNF as feed for metal fuel fabrication. The metal fuel is utilized in a sodium cooled fast reactor and the used FR fuel processed using electrochemical separations. The recovered U/TRU from electrochemical separations is continuously recycled to metal fuel fabrication and irradiated in fast reactors. Waste streams from the aqueous and electrochemical processing are treated and prepared for disposition. Off-gas from the separations and waste processing are also treated to meet current regulations.

As part of the FY-13 and -14 efforts, preliminary process unknowns and research needs to advance the case study and near-term target flowsheets were identified. In FY-14, and again in FY-15, these research needs were updated, expanded and prioritized, with the results presented in this report. This information will be used by the Material Recovery and Waste Form Development (MRWFD) Campaign leadership in research planning for FY-16. Additionally, this information will be incorporated into the next version of the Case Study Report scheduled to be issued September 2015.

\section{AQUEOUS HEADEND PROCESSING}

As was documented in the FY-13 Case Study Report (Law et al. 2013), the headend processes specified for the case study flowsheet are based on existing technology demonstrated at La Hague and Sellafield (Task Order 9 and Willis et al. 2013); therefore, no research, development, or demonstration needs were identified at this time.

For the near-term target flowsheet, the following research needs (in priority order) were identified.

1. The tritium pretreatment process has not been demonstrated on a production scale. A kilogramscale system utilizing a nitrogen dioxide $\left(\mathrm{NO}_{2}\right)$ recirculation loop was previously demonstrated at ORNL using surrogate fuel (DelCul et al. 2014); however, additional work is required to optimize conditions and obtain better measurements of the release fractions of volatile and semi-volatile fission products. Understanding how the off-gas composition (including speciation) changes as a function of the process conditions and fuel type/characteristic is the highest priority task since it will impact the off-gas treatment systems. The total amount of hydrogen (tritium) in used fuel is of the order of parts per billion. The resulting amount of water is too small for the molecular sieve to effectively remove. In practice, some level of humidity will have to be introduced into the recirculation system along with the reagent oxygen. The optimum level of humidity required for 
an efficient tritium removal should be determined. These results will require a confirmation with actual fuel at kilogram scale

2. Larger scale hot cell demonstrations of the tritium pretreatment process using real fuel with higher burnup and shorter cooling time than the previous Dresden fuel tests are needed to quantify species volatilized and conversion rates for high burn-up fuels.

3. One important feature of an advanced tritium pretreatment process is the option to convert uranium in the fuel to the nitrate form. Nitrogen dioxide oxidation of the fuel offers a potential pathway for the direct extraction using TBP/dodecane pre-equilibrated with nitric acid $\left(\mathrm{HNO}_{3}\right)$ for uranium trioxide $\left(\mathrm{UO}_{3}\right)$ or plain $\mathrm{TBP} /$ dodecane for uranyl nitrate $\left(\mathrm{UO}_{2}\left(\mathrm{NO}_{3}\right)_{2}\right)$. Preliminary data indicate that the lanthanides appear to be extracted into the acid pre-equilibrated solvent and rejected using the plain TBP/dodecane. Additional data are required to quantity the degree of separation achieved. A stepwise approach should be considered to obtain the necessary data. This would involve: 1) cold surrogates (e.g., pressing green pellets of uranium dioxide $\left(\mathrm{UO}_{2}\right)$ plus simulated fission products) to obtain preliminary splits, 2) irradiation of one to a few PWR commercial fuel pellets at the High-Flux Isotope Reactor (HFIR) to refine data with a limited (tracer) level of fission product 3) work using a limited quantity of spent fuel (10 to $100 \mathrm{~g}$ scale) to quantify performance with actual material, and 4workusing an intact fuel pin (100's g to a few $\mathrm{kg}$ ) to obtain material balance data. These tests should be conducted in an integrated fashion with the related off-gas treatment studies to determine actual trap recovery and speciation of the volatile components.

4. The impact of the tritium removal process on the quantity and composition of the undissolved solids (UDS) from the dissolution process is not well understood. Samples of the UDS from the CETE demonstration were analyzed (Rudisill et al. 2011); however, no characterization data for UDS generated from the dissolution of fuel treated for the removal of tritium using $\mathrm{NO}_{2}$ are available. A more complete assessment of the effect of the tritium removal process on the amount and composition of the UDS needs to be performed. .

5. The impact of the tritium removal process on the tritium content in the cladding (and the subsequent recycle of the zirconium) needs to be determined.

6. The high specific surface area of the $\mathrm{UO}_{3}$ powder resulting from the tritium removal using $\mathrm{NO}_{2}$ does not require a conventional dissolver as the powder readily dissolves in contact with $\mathrm{HNO}_{3}$ without nitrogen oxide $\left(\mathrm{NO}_{\mathrm{X}}\right)$ emissions (fumeless). In situ dissolution or the use of a dedicated contactor needs to be evaluated. The tritium pretreatment process and the resulting changes in the physical form of the fuel will also have an effect on the amount of volatile components released during dissolution which is not well documented. The composition and quantity of the UDS may also change (as noted in item four).

7. Since the oxidation of $\mathrm{UO}_{2}$ pellets in the tritium removal process results in a significant reduction in density which crumbles the pellets into a fine powder, fuel handling including feeding the treated fuel into the dissolver will require special design considerations and should be evaluated.

\section{HEADEND TRITIUM PRETREATMENT OFF-GAS}

For the near-term target flowsheet, tritium pretreatment is included. For this technology, particular research needs relative to the generated off-gas have been identified and prioritized as follows.

1. Better measurements of the iodine partitioning during the tritium removal process is required. Sample analysis would be greatly aided by processing samples containing I-131 rather than I-129. 
Such samples may be prepared by a short irradiation of low enriched uranium (LEU) targets in HFIR followed by short cooling. Follow-on tests in conjunction with Item 3 in Section 2 is proposed to support the determination of partitioning data.

2. As currently envisioned, the advanced tritium pretreatment process utilizes a closed loop of recirculating oxidant gas in which the volatile fission products accumulate. The recovery of the volatile radionuclides from a gas matrix of this nature has never been demonstrated. The AgZ/3AMS co-adsorption is not an optimal combination for advanced tritium pretreatment. The initial choice for iodine recovery is silver-exchanged mordenite that is acid stable, but at the time it was chosen it had not been tested for iodine capture from gas streams containing more than a few \% NOx. Current studies have shown significant degradation of AgZ under advanced tritium pretreatment off-gas conditions. There is a need to identify and evaluate alternative media and processes to capture the iodine. The process / media needs to be insensitive to NOx and nitric acid vapors that will be present in the off-gas stream. Silver functionalized aerogel should be tested in this environment. Tests at low NOx concentrations showed less degradation in performance than was observed for AgZ. An integrated test of a silver aerogel/3AMS coadsorption system with NO2 present should be tested to determine impacts of the high NO2 levels on iodine capture performance of the silver aerogel. A molten $\mathrm{NaOH}$ scrubber has also been proposed as a possible approach. Other systems using silver nitrate may also be promising and will be examined for their efficacy. Scoping tests of these latter two systems are planned for FY15. If promising integrated tests of these should also be performed.

3. Processes under current investigation to support air/oxygen based tritium pretreatment of UNF include sorption on type 3AMS to sequester the tritiated water. The high concentrations of NOx in the off-gas could cause the tritium to be partially converted to tritiated nitric acid vapor (3HNO3). Information needed to support the NO2 pretreatment process includes, but is not limited to, the speciation of tritium in the off-gas stream (e.g., HTO, 3HNO3, 3HNO2, etc.) and the capacity of the 3AMS sorbent to sequester the tritium-bearing compounds. Cold tests, coinciding with equilibrium calculations, showed that tritium $(3 \mathrm{H})$ was present near room temperature as $3 \mathrm{HNO} 3$ but with the reactor operating at $350^{\circ} \mathrm{C}$ only water was observed. In fact, when $\mathrm{HNO} 3$ was injected into the system it rapidly decomposed into NO2/N2O4 and water. Hydrogen added into the system without any sample in the reactor chamber very slowly transformed into water. The presence of uranium oxide powder or copper oxide it rapidly reacted into water. This water is to be removed by conventional 3A molecular sieve 3A (3AMS) trap operating at room temperature. This needs further demonstration. Alternatives to 3AMS may need to be identified that are more compatible with nitric or other acid gases.

4. The advanced tritium pretreatment process utilizes a closed loop of recirculating oxidant. Volatile gases such as krypton and xenon will be present as a large fraction of the volume. This is a distinct advantage. However, the handling and potential separation and recovery of the noble gases needs to be evaluated using simulants and then confirmed with actual used nuclear fuel at $\mathrm{kg}$ scale.

5. $\mathrm{NO}_{2}$ tritium-pretreatment shows (i) particulate, (ii) $\mathrm{Ru}$ and (iii) $\mathrm{I}_{2}$ traps in series. This integrated system generates several critical questions. 1) What is the behavior of $\mathrm{Ru}$ on the particulate filter? What is the behavior of $I_{2}$ on the particulate filter? 2) What is the behavior of $I_{2}$ on the Ru trap? 3) Is there any Ru carryover onto the $\mathrm{I}_{2}$ trap? During CETE we have no evidence of any Ru or other semi-volatile carryover but this should be confirmed with tests with actual fuel. 4) Is there sufficient water with the $\mathrm{NO}_{2}$, and in the recycle of the $\mathrm{NO}_{2}$, to carry sufficient $\mathrm{HNO}_{3}$ to affect the filter? If so, what is the expected lifetime of the filters? 5) What are the possible disposition pathways for the filters?

6. Demonstration of the performance of 3A MS when exposed to NOx for extended periods of time. 
7. Extended testing of the abatement / trapping components in a recirculating $\mathrm{NO}_{2}$ loop is need with the appropriate introduction of the species to be recovered. Follow-on tests in conjunction with Item 5 in Section 2 is proposed to support the determination of an integrated capture system using actual fuel.

\section{AQUEOUS U/PU/Np RECOVERY}

The reference $\mathrm{U} / \mathrm{Pu} / \mathrm{Np}$ recovery process, Co-decontamination, is based on a co-extraction of $\mathrm{U}, \mathrm{Pu}$, and $\mathrm{Np}$, followed by selective stripping to recover product streams containing $\mathrm{U} / \mathrm{Pu} / \mathrm{Np}$ and a second product stream containing the bulk $\mathrm{U}$. The Co-decontamination process is built on very well-understood solvent extraction chemistry based on the use of tributyl phosphate (TBP) and hinges on regulating the behavior of key species involved in the separations rather than on significant new advances in the process.

For the case study/near-term target case $\mathrm{U} / \mathrm{Pu} / \mathrm{Np}$ recovery flowsheet, the following research needs (in priority order) were identified.

1. Flowsheet validation testing (for fission products) using tracers and non-radioactive simulants. This includes batch contact measurement of Tc distribution ratios under flowsheet conditions to optimize recovery of Tc and minimize extraction of Mo, $\mathrm{Zr}$ and Ru. Additionally, the behavior of these components should be validated through flowsheet testing.

2. Characterization of $\mathrm{Np}$ valence behavior in nitric acid solutions under conditions expected for the reference flowsheet. Controlling the $\mathrm{Np}$ behavior is the key to determining the feed composition for the process in absence of other requirements, such as corrosion, waste compatibility, product quality specifications, etc. The addition of redox agents is central to this control, as is the production of nitrous acid by radiolysis. These effects need to be more fully understood in order to define the requirements on the implementation of the flowsheet for testing. Bench-scale tests are required to define the chemistry while tests on process equipment are required to evaluate implementation in discrete stages for scale-up, and in full multi-section flowsheets.

3. Testing of the Co-decontamination flowsheet to evaluate the operating envelope (U and nitric acid concentrations, O:A ratios), for attaining the targeted U:TRU ratio in U/TRU strip.

4. Testing of combined $U$ and Tc strip to verify Tc behavior

5. The case study flowsheet is intended to be equipment independent. However, initial testing makes it clear that equipment selection will significantly impact flowsheet performance. It will be important to better characterize how the equipment affects the flowsheet through tests that isolate different factors. This will require benchtop tests to characterize chemistry in tandem with companion tests of the same chemistry on test equipment.

6. Low-acid dissolution following advanced tritium pretreatment offers the opportunity to eliminate the high acid raffinate. This could also significantly change the U/Tc split. Need to confirm that Tc remains un-extracted while still effectively extracting the U/Pu. This would add a significant impact to feed preparation which defines the starting point for the flowsheet design

7. Determine and test the need for a second U/TRU clean-up cycle based flowsheet testing results and fuel requirements. Although the tracer tests with contactors can provide information on purities, it will be difficult to truly address without a sufficient number of stages (for simulants) or actual fuel.

8. Development of predictive Np oxidation chemistry model for inclusion in the Argon Model for Universal Solvent Extraction (AMUSE/DyAMUSE). Re-evaluation of process flowsheet for different $\mathrm{Np}, \mathrm{U} / \mathrm{TRU}$, Fission product distributions and impacts on other extracting species. 
9. Test entire Co-decontamination flowsheet with surrogates and/or tracers initially followed by testing with actual used nuclear fuel.

\section{AQUEOUS TRU PRODUCT SOLIDIFICATION}

The solidification process presents more unknowns as there are relatively little data available for conversion of mixed actinide nitrates to mixed actinide oxides. The modified direct denitration (MDD) process, at least in principle, should work for both products coming from the Co-decontamination process and particularly the actinide-lanthanide separations. However, there has been relatively little experience beyond the lab-scale with oxides other than those of pure uranium. The ratio of nitric acid to metal in the two products is an order of magnitude, or more, higher than the ratios reported for MDD feeds in the literature. Addition of formaldehyde was included in the case study flowsheet, but no such treatment is reported in association with the process in the literature. Moreover, the product of the initial denitration is primarily $\mathrm{UO}_{3}$. Production of $\mathrm{UO}_{2}$, for extended storage or if direct transfer to fuel fabrication is desired, requires a reduction step which has been included in the case study flowsheet. It is not clear that such a step is necessary for extended storage as either oxide form may be suitable with appropriate packaging and if maintained in an appropriate environment. Testing with mixed metal concentrates of a composition consistent to those coming from the separations at a reasonable scale would be required to determine the effectiveness, consistency and controllability of the MDD process. Acetohydroxamic Acid (AHA), and its decomposition products, acetic acid and hydroxyl amine nitrate, will be present in significant quantity in the U/Np/Pu product stream; although it can be expected to decompose in the MDD process, its behavior in that process has not been investigated. Other technologies may also be effective for mixed product recovery, such as oxalate precipitation, which has been tested in France.

For the case study/near-term target case TRU product solidification process the following research needs (in priority order) were identified:

1. Perform a preliminary evaluation of candidate mixed actinide solidification processes. Determine fate of AHA and decomposition products, identify reaction products. Determine operating envelope and evaluate product morphology

2. Test candidate mixed oxide solidification with surrogates at lab-scale

3. Develop process for engineering-scale tests/equipment for mixed oxide solidification

\section{AQUEOUS ACTINIDE-LANTHANIDE SEPARATION}

The case study flowsheet for separating the trivalent actinides (i.e., Am and $\mathrm{Cm}$ ) from the fission product lanthanides, and all the other fission products in the high level waste stream arising from the Codecontamination process, involves two distinct process steps. First, the trivalent actinides and lanthanides are co-extracted using the transuranic extraction (TRUEX) process. Second, the combined actinide/lanthanide product from the TRUEX process is subjected to the Trivalent Actinide Lanthanide Separations by Phosphorus Agent Extraction from Aqueous Complexes (TALSPEAK) process to separate the lanthanides from the actinides. This 2-step tandem approach to recovering the trivalent actinides has been demonstrated with irradiated commercial fuel at the laboratory scale. It is recognized that much more development work is necessary if the TRUEX/TALSPEAK case study flowsheet were to be implemented. However, due to the complexity and limitations of this approach, the research efforts identified below focus on advancing the near-term target flowsheet.

For the near-term target case, the TALSPEAK process is replaced with the Advanced TALSPEAK process. In the Advanced TALSPEAK process, the Bis-(2-Ethylhexyl) Phosphoric Acid (HDEHP) extractant is replaced with 2-ethylhexylphosphonic acid mono-2-ethylhexyl ester (HEH[EHP]). ${ }^{i}$ The key 
advantages of switching to the HEH[EHP] extractant are reported to be: less dependence of the process performance on the aqueous solution $\mathrm{pH}$, more predictable extraction behavior, and more rapid extraction kinetics. Much progress has been made in developing the Advanced TALSPEAK chemistry over the last two years, but critical research needs still remain.

For the near-term target actinide-lanthanide separation flowsheet the following research needs (in priority order) were identified.

1. Verify the performance of alternative aqueous phase compositions for the Advanced TALSPEAK system in single-stage centrifugal contactor experiments. The top candidate aqueous phase compositions are $0.25 \mathrm{~mol} / \mathrm{L} \mathrm{NTA}+0.2 \mathrm{~mol} / \mathrm{L}$ citrate at $\mathrm{pH} 3.1$, and $0.125 \mathrm{~mol} / \mathrm{L}$ HEDTA +0.6 $\mathrm{mol} / \mathrm{L}$ citrate buffer at $\mathrm{pH}$ 2.6. The single-stage experiments should provide information on the effective distribution behavior the lanthanide elements (lanthanum through gadolinium, excluding promethium) in the Advanced TALSPEAK process as a function of flowrate rates using contactor equipment. These data are needed to support flowsheet design efforts. Based on the lanthanide results, the distribution behavior of americium under a specific flow condition will also need to be determined.

2. In previous investigations of the case study TRUEX + TALSPEAK tandem process, it was demonstrated that the TRUEX solvent could be stripped with a DTPA/lactic acid solution, which was then suitable for feed (after minor $\mathrm{pH}$ adjustment) to the TALSPEAK process. For the Advanced TALSPEAK process, a different complexant/buffer combination is used. Research is needed to determine if this different complexant/buffer combination can serve as a suitable stripping agent for the TRUEX process, so that the actinide/lanthanide product from TRUEX can be fed directly to the Advanced TALSPEAK process.

3. Using the optimized aqueous phases tested in item 1, evaluate the sensitivity of the Advanced TALSPEAK process to variations in processing conditions. Parameters of interest include the $\mathrm{pH}$ of the feed solution, variations in the concentrations of solution components, and temperature.

4. Develop and test Advanced TALSPEAK flowsheet using simulated, and eventually actual, TRUEX raffinate.

5. The methods for washing degradation products from the TALSPEAK and Advanced TALSPEAK solvents are virtually unknown. Research is needed into developing methods for restoring the HDEHP and HEH[EHP] solvents so that they can be recycled in the process.

Although the near-term target case is currently the Advanced TALSPEAK process, development of a more robust and efficient method of minor actinide separation is a key focus of the MRWFD campaign with considerable research efforts focused on development of single step process, such as ALSEP or processes based upon the separation of higher oxidation states of americium. Therefore, focused research efforts of a high program priority, not detailed in this report, are ongoing. Currently, ALSEP is considered the most mature alternative process with efforts focusing on the demonstration of the flowsheet with radiotraced simulants in the next year.

\section{AQUEOUS OFF-GAS TREATMENT}

For the case study/ near-term target case Off-gas separation flowsheets the following research needs (in priority order) were identified.

1. Demonstrate the efficiency of $\mathrm{AgZ}$ and alternate sorbents under increasingly more prototypic dissolver off-gas (DOG) and vessel off-gas (VOG) stream conditions to capture and control the iodine species that will be present. The focus of this effort will be on organic iodides and very 
dilute streams. The data that are needed include changes in capacity and capture efficiency as a function of stream conditions. Evaluate efficiency of Ag-functionalized aerogels under prototypic off-gas conditions.

2. Demonstrate a multi-bed system for the recovery of krypton from air at room temperature with MOF and zeolite materials. Confirm capacity, adsorption rates, desorption rates, etc.

3. Obtain data from the dissolution of actual UNF to evaluate the iodine evolution kinetics, the fraction remaining in solution, and the species of iodine not evolved. There is ample evidence in the literature that the iodine-bearing species that are evolved during UNF dissolution are not fully known. A test plan intended to identify these unknown species and their concentrations should be created and executed.

4. Determine performance of promising alternate iodine sorbents under operating conditions. Determine extent of co-adsorption on these materials.

5. Demonstrate integration of individual off-gas capture systems at bench scale or larger. Evaluate the combined system efficiency; determine sequencing, co-adsorption / interoperability issues.

6. Determine if the lesser forms of iodine (HI, $\mathrm{HIO}, \mathrm{CH}_{3} \mathrm{I}$, etc) penetrate through the iodine bed to any extent and impact downstream processes. What is the behavior of these iodine forms in the (i) $\mathrm{NO}_{\mathrm{x}}$ scrubber, (ii) carbon scrubber, (iii) $\mathrm{Kr} / \mathrm{Xe}$ traps? Are any observed effects or compounds cumulative over operating times?

7. As currently envisioned, the advanced tritium pretreatment process utilizes a closed loop of recirculating oxidant gas in which the volatile fission products accumulate. The recovery of the volatile radionuclides from a gas matrix of this nature has never been demonstrated. The initial choice for iodine recovery is silver-exchanged mordenite that is acid stable, but at the time it was chosen it had not been tested for iodine capture from gas streams containing more than a few $\%$ $\mathrm{NO}_{\mathrm{x}}$. Current studies have shown significant degradation of $\mathrm{AgZ}$ under advanced tritium pretreatment off-gas conditions. There is a need to identify and evaluate alternative media and processes to capture the iodine. The process / media needs to be insensitive to $\mathrm{NO}_{\mathrm{x}}$ and nitric acid vapors that will be present in the off-gas stream. Silver functionalized aerogel should be tested in this environment. Tests at low NOx concentrations showed less degradation in performance than was observed for $\mathrm{AgZ}$. A molten $\mathrm{NaOH}$ scrubber has also been proposed as a possible approach. Other systems using silver nitrate may also be promising and will be examined for their efficacy. Scoping tests of these two systems are planned for FY15.

8. In addition to the volatile species, the behavior of the semi-volatile elements needs to be evaluated. The semi-volatiles that arise in head-end pretreatment processes need to be identified. Semi-volatile concentrations in the off-gas stream need to be quantified and the effects (if any) of high oxidant concentrations on forming volatile compounds of these elements at relevant tritium pretreatment conditions need to be characterized. Of initial interest is the behavior of ruthenium under advanced tritium pretreatment conditions.

9. Characterization of $\mathrm{I}_{2}$ behavior in the DOG (including any potential co-adsorption) on a potential Ru trap should be completed.

10. Perform a volatile species material balance on an intact fuel pin as the pin is processed through shearing, tritium pretreatment, and dissolution. Quantification of the release of semi-volatiles is also needed.

11. Obtain data from plant operations through international collaboration on iodine emissions (origins and speciation). 
12. Understand long term effects of the build-up of $\mathrm{Rb}$ in ${ }^{85} \mathrm{Kr}$ storage systems. Continue the analysis of the legacy ${ }^{85} \mathrm{Kr}$ capsules. Prepare new samples for extended storage.

13. Demonstrate the radiation stability of $\mathrm{Kr}$ capture MOFs and verify the radiolytic stability of mordenite form sorbents. Need to understand long term stability when loaded with ${ }^{85} \mathrm{Kr}$.

14. Demonstrate off-gas capture technologies on hot off-gas streams. This could be accomplished as opportunities become available in the US or through international collaborations.

15. Processes under current investigation to support air/oxygen based tritium pretreatment of UNF include sorption on type 3A molecular sieves (3AMS) to sequester the tritiated water. The high concentrations of $\mathrm{NO}_{\mathrm{x}}$ in the off-gas could cause the tritium to be partially converted to tritiated nitric acid vapor $\left({ }^{3} \mathrm{HNO}_{3}\right)$. Information needed to support the $\mathrm{NO}_{2}$ pretreatment process includes, but is not limited to, the speciation of tritium in the off-gas stream (e.g, $\mathrm{HTO},{ }^{3} \mathrm{HNO}_{3},{ }^{3} \mathrm{HNO}_{2}$, etc.) and the capacity of the $3 \mathrm{AMS}$ sorbent to sequester the tritium-bearing compounds.

Alternatives to $3 \mathrm{AMS}$ may need to be identified that are more compatible with nitric or other acid gases. 20. In all traps that accumulate radioactive materials, information is needed on how radiolysis of the components in the gas stream affects downstream off-gas treatment steps. (Most of the experiments done to-date are non-rad and we have limited experience there.) The results could the impact the location of the treatment systems. Are there major impacts, if any, from self-irradiation or would shielding or relocation reduce effects?

\section{AQUEOUS HIGH-LEVEL WASTE MANAGEMENT}

The high-level waste (HLW) vitrification processes specified for the case study flowsheet is a hybrid based on existing technologies demonstrated at full scale with actual HLW. (Vienna 2010) The feed preparation is assumed to be evaporated sufficiently to support slurry feed to the melter (deployed in Germany, Belgium, Japan, and the U.S.). The melter will be a cold-crucible induction melter (deployed in France where it is coupled to a calciner for intermediate-level waste (ILW) and HLW and used in Russia and Korea for ILW). The melter off-gas treatment system components are selected to be consistent with the liquid-fed HLW melter that meets U.S. criteria for plant emissions (single components separately deployed in the U.S. and internationally). The canister, sealing, decontamination systems selected are based directly on those deployed in France and the U.K. and, in the case of the canister, Japan. Although each process step has been demonstrated, the combined system has not. A coupled process demonstration with representative simulated waste from the case study flowsheet is the research need. The composition of the waste depends, somewhat, on the amount and composition of solvent wash solutions plus other secondary waste streams and their potential addition to the HLW stream.

Additionally, the scientific underpinning for glass long-term performance models is a critical gap that needs to be addressed to: 1) reduce the conservatism in current glass performance models, 2) garner international consensus on corrosion rate models, and 3) reduce the dependence on expensive engineered barriers in the disposal system. An on-going six-nation collaboration on glass corrosion mechanisms and modeling will be continued to develop an international consensus glass corrosion model. This includes model development for interface with generic repository performance models being developed under the Used Fuel Disposition Campaign.

The near-term target flowsheet includes immobilization of two HLW streams 1) a combined TRUEX raffinate and advanced TALSPEAK product that is vitrified with associated secondary wastes and 2) soluble technetium and undissolved solids stream that is converted to a metal waste form. The glass ceramic development, demonstration, and qualification activities are discussed in detail in the Preliminary Technology Maturation Plan for Immobilization of High-Level Waste in Glass-Ceramics. (Vienna 2012) The prioritized list of needs include: 
1. Complete paper study to characterize, estimate volumes and ranges, and simulate waste(s) to be treated.

2. Perform laboratory scale glass ceramic testing to include formulation optimization, durability testing and phase characterization across range of potential compositions and temperature histories.

3. Perform melter and off-gas testing with simulants to include development of mass balance, equipment functional testing, development of design data, and qualification testing.

4. Issue a waste compliance plan to describe the waste form durability testing and waste form compliance methods to be employed in production.

The metal waste form is still in the conceptual stage of development. The general concept is to separate the UDS by clarification of the dissolver solution; selectively strip $\mathrm{TcO}_{4}{ }^{-}$from TBP in the U/Pu/Np Recovery Process. This is then reduced to a suspension of $\mathrm{TcO}_{2} \cdot \mathrm{nH}_{2} \mathrm{O}$, blended with the UDS, dried, and reduced to a metal alloy, except for the $\mathrm{Zr}$ that remains as hydrated $\mathrm{ZrO}_{2}$. The reduced materials are reacted and consolidated into monolithic metal waste forms with hot-isostatic pressing (HIP). The prioritized research needs for this waste form include:

1. Process development and demonstration to include methods of $\mathrm{TcO}_{4}$ separation from uranium and precipitation as $\mathrm{TcO}_{2} \cdot \mathrm{nH}_{2} \mathrm{O}$, methods to convert UDS and Tc oxides into metal for consolidation, and HIP method for reacting and consolidating the final waste form that is a mixture of a metal allow and $\mathrm{ZrO}_{2}$.

2. Optimize the formulation of the metal waste form composition for performance and processability.

3. Measure and model the chemical durability of the waste forms to include bare metal corrosion rate, potential for passivation, and corrosion of alteration products. Develop a model of the waste form performance as a function of solution composition, temperature, and waste form composition and characteristics.

Analyses are also required to determine the relative value of separating the Tc and UDS into a separate waste form or combining them with liquid HLW for a single combined HLW form. The latter is similar to previous studies in which the separation of $\mathrm{Cs} / \mathrm{Sr}$ and transition metal fission products from the HLW waste stream was studied. (Gombert et al. 2008)

\section{TREATMENT OF AQUEOUS PROCESS WASTES}

A number of distinct streams are considered in the Treatment of Aqueous Process Wastes Section of the report. Most of these streams are managed by the well developed and deployed technologies of evaporation, compaction, and/or cementation. A couple specific streams can be somewhat challenging and require some technology development and demonstration. Those streams include: 1) the silver sorbents containing radioiodine and chlorine, 2) zirconium hulls, and 3) high volume tritiated water.

\subsection{Silver Sorbents}

${ }^{129}$ Iodine and ${ }^{36} \mathrm{Cl}$ are mobile in disposal environments and have sufficiently long half-lives to be significant repository dose contributors. (Swift and Nutt 2012) They are also somewhat volatile in thermal waste form fabrication processes. Therefore they are challenging to effectively immobilize. The case study flowsheet includes capture of halides on $\mathrm{AgZ}$ which is crushed, mixed with a glass frit, and sintered into a glass composite material (GCM) waste form. In the near-term target flowsheet the halides are 
captured on a silver functionalized aerogel which is consolidated into fused silica waste form with HUP. The research priorities are similar for both proposed processes:

1. Develop, demonstrate, and optimize the processes for iodine capture media Immobilization including off-gas management. Determine composition of effluent from conversion processes (i.e., iodine loss, etc.).

2. Determine the long-term chemical durability of the waste forms to include development of phenomenological models for waste form degradation and halide release, quantification of waste form alteration parameters, and validation of performance models. (Note: We need to determine appropriate durability testing methodology for iodine waste forms to support this R\&D need.)

3. Development of alternative materials and methods for capture and immobilization of the iodine.

\subsection{Zirconium Hulls}

The zirconium hulls are generally sufficiently contaminated to require deep geological disposal if they are disposed. The amount (both volume and mass) of hulls disposed of by commonly applied methods of super compaction and cementation are far greater than the other HLW streams generated during UNF reprocessing. Reduction of the amount of hulls for disposal is therefore a significant potential cost savings. In the case study flowsheet the hulls are super compacted by the process currently employed at the LaHague facility in France and require no research. The near-term target flowsheet assumes purification of the $\mathrm{Zr}$ to enable either reuse in nuclear applications or at a minimum, disposal as low-level waste. The research requirements for the $\mathrm{Zr}$ purification process are described in the Roadmap for Zirconium Recovery/Recycle Process Development. (Collins et al. 2012) The prioritized list of research activities include:

1. Criticality analysis.

2. Process chemistry development to include management of chlorinated ash and off-gas treatment process. A method of removal of residual chlorine from the recycle process ash will need to be incorporated. Chemistry reported in the literature indicates it works, but we have never done it and we need to verify and optimize the conditions.

3. Scaled-up process development and demonstration using unirradiated hulls followed by irradiated hulls. Metal equipment for this work has been fabricated, assembled, and is currently undergoing readiness operability testing.

4. Determine effects of hydrous oxide coatings on rate of chlorination. (Effects of anhydrous oxide layers have been quantified and evaluated in work accomplished during FY 2014.)

5. Determine product purity produced from high burn-up UNF cladding. Encouraging results were obtained from feasibility tests with actual UNF and non rad tests with zirconium alloy cladding.

6. Determine the fate of residual tritium in cladding. This is a two part effort. First, preliminary tests have shown that only a limited amount of tritium is released at temperatures up to $700^{\circ} \mathrm{C}$ over 24 hours. However, by retaining the cladding at $700^{\circ} \mathrm{C}$ for an additional 24 hours virtually all of the tritium was released. Additional confirmatory tests are needed. Second, we need to evaluate the capture and disposal of tritiated $\mathrm{HCl}$. This includes the evaluation of molecular sieve to dry the Cl-containing stream and evaluation of the neutralization and grouting of the water

7. Refined reactor/process design to optimize method of purification for salt product. Initial non-rad tests have identified chemical reductant additions that are effective.

8. Perform process evaluations to include equipment selection, general layouts, cost estimates, and mass balances. 


\subsection{Tritiated Water}

In the case study flowsheet tritium will distribute to multiple liquid waste streams generated in the aqueous process. In currently operating reprocessing facilities tritiated water is discharged to the sea where nearly infinite isotopic dilution renders it benign. The volume of such a stream is therefore unimportant. However in the U.S. it is not currently possible to manage tritium by sea or air discharge so solidification and disposal are assumed. For such a large volume of waste, this can be costly. Concepts for minimizing the volume of the tritiated water streams have been proposed in Task 9 Report Improving the Estimates of Waste from Recycling, Sub-Task 5: Final Technical Report. (AFS 2013) Even if this unproven technology is found effective, the volume of tritiated water for solidification is still great. A separate option was proposed in LWR UOX and MOX Fuel Recycle and LWR MOX and Fast Reactor Fuel Fabrication Waste Estimates (Willis et al. 2013, where the tritium is concentrated in the combined electrolysis catalytic exchange (CECE) technology. The much smaller volume of tritiated water is then solidified. Unfortunately, the CECE process is both a cost and energy intensive process. Significant cost saving can be realized if the tritium can be concentrated to a relatively low volume stream with a more cost effective method than current CECE. The research need is to develop and demonstrate an innovative, cost effective, method for tritium concentration from high volume water streams.

At present, there is a critical shortage of ${ }^{3} \mathrm{He}$ for use in neutron detectors and for medical uses. A study is needed to determine the feasibility of producing ${ }^{3} \mathrm{He}$ from the $\mathrm{H}^{3} \mathrm{HO}$ and ${ }^{3} \mathrm{H}_{2} \mathrm{O}$ and, if feasible, what waste form is optimum for this use.

\section{ELECTROCHEMICAL PROCESSING}

The main unit operation in the electrochemical process flowsheet (base case and near-term target) is the uranium electrorefiner, which separates a purified uranium product and a U/TRU product from the used nuclear fuel dissolved into a $\mathrm{LiCl} / \mathrm{KCl}$ molten salt eutectic. Recovery of a purified uranium product in the electrorefiner is the most mature of the electrochemical technologies as it has been the focus of process development. Pilot-scale operation of a uranium electrorefiner in a remote environment has been demonstrated at the Idaho National Laboratory in the stabilization of spent fuel from the Experimental Breeder Reactor II. Operations data from these electrorefiners were used to design a commercial prototype module that was constructed and performance tested at Argonne National Laboratory. Experimental evaluation of the prototype module led to the development of a scalable, semi-continuous system for uranium electrorefining.

Although less technically mature than uranium recovery in the electrorefiner, co-deposition methods for U/TRU recovery in the electrorefiner have been conceived and are under development. Two methods have been proposed for U/TRU recovery in the electrorefiner, liquid cadmium cathode and solid cathode, and experimental evaluation of these two technologies is ongoing. Positive experimental results have been obtained for both technologies, but additional experimentation is needed to fully define process efficiency including the extent of lanthanide carryover with the U/TRU product. The liquid cadmium cathode, with evaluation at the engineering-scale in a remote environment, is the more mature of the two technologies but difficulties encountered with dendrite formation and the crucible system used during the experimentation limited the number of tests completed thus questions remain concerning the technology such as the extent of lanthanide carryover to the U/TRU product as well as resolution of potential operating issues. Only recently have studies of the solid cathode technology been conducted, although the results of the tests have been promising, additional evaluation at larger scale with more complex chemical systems is warranted. Calculations predict that the absence of cadmium will drastically decrease the concentration of lanthanides in the solid cathode U/TRU product as compared to the liquid cadmium cathode U/TRU product. 
Beyond continued maturation of the U/TRU recovery process, another potential need for the electrochemical process is the area of fission product recovery technologies. Separation of fission products may be helpful to limit the fission product impurity in the actinide products as well as allow recycle of the $\mathrm{LiCl} / \mathrm{KCl}$ salt and minimize waste. Numerous techniques ranging from electrolysis to reductive extraction have been conceived and tested for fission product recovery from the electrolyte salt, but no single technique has matured beyond bench-scale. For a complete flowsheet evaluation, fission product recovery technologies must be matured and those down-selected for a pilot-scale demonstration brought to the same level of technical maturity as the electrorefining process. Similarly, process monitoring and safeguards technologies have been experimentally evaluated at the bench-scale, but technology maturation is required for implementation at the pilot-scale.

As the maturity of the unit operations reach similar stages of development, close-coupled testing of the systems should be completed to assess product recovery efficiency and quality. Simulated fuels containing actinides could be used in early studies to evaluate the close-coupled processes but irradiated materials must be used in follow-on studies. Ultimately, an integrated flowsheet demonstration must be completed at a meaningful scale to allow for a thorough assessment of the process chemistry and insight into integration of the unit operations. An essential component of this type of study is to identify process and equipment improvements as well as methods to mitigate process losses and the amount of secondary waste produced in a fuel treatment demonstration. As the technical maturity of the unit operation increases, the development focus should move from that of process chemistry to that of process chemistry and engineering.

Several components of the near-term target flowsheet are currently being developed and evaluated as part of the Fuel Cycle Technology Program. Testing of the solid U/TRU cathode technology is underway to develop the design data needed for technology scale-up. Previous studies demonstrated process viability using mixtures of actinide and lanthanide chlorides, established boundary conditions for efficient cell operation, and yielded a fundamental understanding of the process chemistry. Current laboratory-scale experimentation provides insight into the co-deposition behavior including product morphology, nucleation, and deposition rates of uranium and the transuranic elements under a variety of operating conditions. Kilogram-scale experiments with uranium and transuranic element surrogates are designed to provide design data for equipment scale-up. The combination of the laboratory- and kilogram-scale testing provides a solid foundation for process scale-up and development. These activities should continue in FY15 and beyond to continue to mature the technology.

Fission product recovery processes in the early stages of development include electrolysis, which is proposed for actinide and lanthanide recovery, and the electrochemical recovery of cesium via the ion selective membrane. The feasibility of each technology has been demonstrated through small-scale experiments. Additional tests are underway to identify operating conditions for the electrochemical system and correlate those conditions with process efficiency and product quality. For example during the actinide drawdown process designed to limit actinide loss to the waste stream, the degree of lanthanide carryover with the actinide product, which is to be recycled to the refiner, must be experimentally established to assess flowsheet efficiency. These tests must continue in FY15 and beyond to allow for sufficient experimental data to be collected for an assessment of the technology and its suitability for use in the near-term flowsheet.

The above research needs are summarized below in priority order.

1. Testing of the solid cathode technology to determine the extent of lanthanide carryover with the U/TRU product and to develop the design data needed for technology scale-up. This work includes laboratory-scale testing of codeposition behavior as well as kilogram-scale testing to 
provide design data. Results from this task will allow for comparison of the solid cathode and liquid cadmium cathode technology and selection of a technology for further development. Lanthanide carryover data are needed for the liquid cadmium cathode system as well, but these are expected to be determined as part of the Joint Fuel Cycle Studies program.

2. Development of fission product recovery processes (e.g. through electrolysis, ion selective membrane, or other methods). Operating conditions, process efficiency and product quality evaluations should be performed to support selection of an appropriate technology for fission product recovery. The technology selection process should include an evaluation of data from previous technology development studies such as chemical reduction and reductive extraction as well as the electrolytic methods.

3. Close-coupled testing of the developed electrochemical separation and fission product recovery systems should be completed to assess product recovery efficiency and quality. This testing should be performed over several batches of a representative fuel and involve all unit operations (electrorefining, cathode processing, actinide drawdown, fission product drawdown, etc.) These data will be used to update mass balance values, which are currently based on assumptions drawn from the data currently available.

4. During electrorefining of metallic fuel, there is a competing goal of high recovery (i.e., high dissolution) of actinides and low recovery (i.e., low dissolution) of zirconium. However, in practice recovery of zirconium might accompany the recovery of actinides during anodic dissolution of the fuel. Methods to manage zirconium during the electrorefining process should be identified and evaluated.

\section{ELECTROCHEMICAL OFF-GAS TREATMENT}

The requirements to manage the volatile radionuclides will be the same for the E-Chem process as for the aqueous-based processes. However, the bulk of the iodine is expected to remain in the salt and not volatilize. The requirements for krypton capture imposed by 40 CFR 190 may require $\mathrm{Kr}$ capture. The current design of the processing equipment allows the release of volatile components to the cell atmosphere. Release of process gases into the cell atmosphere results in consequences that deserve further evaluation when the research needs listed below are addressed. For example, this release then requires the treatment of a slip stream from the cell gas to be processed. It is assumed that the cell atmosphere is argon. Similar approaches to the recovery of krypton should be viable for this application. These include cryogenic recovery of krypton and the use of solid sorbents.

For the case study/near-term target case electrochemical off-gas treatment flowsheets, the following research needs (in priority order) were identified.

1. Determine amount of tritium entering the E-chem process and fate of the tritium during processing.

2. Volatile species adsorption testing needs to be performed specific to $\mathrm{Kr}$ capture from the cell atmosphere. This includes the development and testing of solid adsorbants to support the nearterm target flowsheet and the design and testing of the off-gas treatment systems for E-chem processes.

3. Determine if greater than $99.9 \%$ iodine retention is achieved within the E-chem process and Echem waste processing to meet off-gas emission requirements. These data are needed to determine if any iodine recovery is required for the E-chem off-gas. 


\section{ELECTROCHEMICAL HIGH LEVEL WASTES}

Two HLW streams are generated by the electrochemical processing of metal fast reactor fuels: 1) spent $[\mathrm{Na}, \mathrm{Li}, \mathrm{K}] \mathrm{Cl}$ salt containing fission products and trace actinides and 2) metal undissolved solids containing stainless steel hulls, trace actinides, and fission products more noble than uranium.

\subsection{Salt Waste}

The salt waste (in the case study flowsheet) and salt waste plus metallic lanthanide particles (in the nearterm target flowsheet) are adhered to a zeolite, mixed with a glass frit, and sintered into a ceramic waste form (CWF) with sodalite, lanthanide oxides, and other crystalline components embedded in a continuous borosilicate waste form. This waste form was developed for waste streams from the treatment of sodium bonded fuel in which uranium and plutonium were recovered, but, the minor actinides were not. The waste salt was to be immobilized in CWF at a relatively low loading as described in the Ceramic Waste Form Handbook. (Ebert et al. 1999) Scale-up tests of this process using non-radioactive simulants was demonstrated with relatively low waste loading (e.g., $7.5 \mathrm{wt} \%$ ).(Morrison et al. 2010, Morrison and Bateman 2010, and Morrison 2011)

What limits the useful service-life of ER salt in the electrorefiner is not currently understood. The highest priority is to develop a detailed understanding of the useful life of the salt through a combination of modeling and experiments. Once it is determined what limits the useful life, research can then be performed to optimize processing operation to utilize the salt to the greatest extent practical. CWF process and composition optimization is a second high priority research activity. Study of the chemical durability of the waste form is also needed. Research should address the development of an improved waste process/form that allows for chloride recycle. The latter is important for both improved economics of waste management and avoidance of high $\mathrm{Cl}$ mass disposal in a repository environment which may impact repository design and performance.

\subsection{Metal Waste}

The metal waste in both the case study and near-term target flowsheet are to be melted into monolithic ingots as a final waste form. This process has been developed and deployed for DOE sodium bonded fuel treatment at Idaho National Laboratory as described in the Metal Waste Form Handbook (Abraham et al. 1999) and demonstrated full scale as described in Characterization of Irradiated Metal Waste from the Pyrometallurgical Treatment of Used EBR-II Fuel. (Westphal et al. 2013) The process and qualification activities for this waste form are all based on $316 \mathrm{SS}$ based fuel cladding, while the reference (and most likely) cladding for FR fuel is HT-9. The research needs include

1. Metal waste form process and composition optimization using HT-9 based materials.

2. Demonstration of an optimized composition and process for the proposed waste streams.

3. Development of performance models.

\section{INTEGRATED FLOWSHEET TESTING}

The research needs identified and prioritized within this report generally relate to specific sections of the overall flowsheet (e.g., headend, An/Ln separation) or individual unit operations. Many challenges in deployment of a flowsheet result from interfaces between unit operations. Therefore, integrated testing of 
the case-study flowsheets will be necessary as they reach the appropriate level of maturity. This will likely include laboratory-scale testing using radiotraced feed simulants and actual UNF. Also, engineering-scale testing using depleted uranium will be required. The near-term integrated testing needs within specific portions of the overall flowsheet (e.g., integration of off-gas capture systems) have been identified above. However, specific research needs for integration amongst flowsheet sections will be developed in future updates of this report as maturity levels increase.

\section{REFERENCES}

Abraham, D.P., S.M. Mcdeavitt, D.D. Keiser, S.G. Johnson, M.L. Adamic, S.A. Barker, T.D.

Disanto, S.M. Frank, J.R. Krsul, M. Noy, J.W. Richardson, and B.R. Westphal, Metal Waste Form Handbook, ANL-NT-121, Argonne National Laboratory, Argonne, IL (March 1999).

Areva Federal Services, Task 9 Report - Improving the Estimates of Waste from Recycling, SubTask 5: Final Technical Report, RPT-3007827-001, AREVA Federal Services, Charlotte, NC (March 2013).

Collins,E. D., B.B. Spencer, G.D. Delcul, R.R. Brunson, and J.A. Johnson, Roadmap for Zirconium Recovery/Recycle Process Development, FCRD-SWF-2013-000074, Oak Ridge National Laboratory, Oak Ridge, TN (December 2012).

DelCul, G. D., R. D. Hunt, B. B. Spencer, E. D. Collins, and R. T. Jubin, Kilogram-Scale Tritium Pretreatment System Utilizing NOx Recirculation Loop, FCRD-SWF-2014-000024, Oak Ridge National Laboratory, Oak Ridge, TN (August 2014).

Ebert, W. L., D.W. Esh, S.M. Frank, K.M. Goff, M.C. Hash, S.G. Johnson, M.A. Lewis, L.R. Morss, T.L. Moschetti, T.P. O'holleran, M.K. Richmann, J. Riley, W. P., L.J. Simpson, W. Sinkler, M.L. Stanley, C.D. Tatko, D.J. Wronkiewicz, J.P. Ackerman, K.A. Arbesman, K.J. Bateman, T.J. Battisti, D.G. Cummings, T. Disanto, M.L. Gougar, K.L. Hirsche, S.E. Kaps, L. Leibowitz, J.S. Luo, M. Noy, H. Retzer, M.F. Simpson, D. Sun, A.R. Warren, and V.N. Zyryanov, Ceramic Waste Form Handbook, ANL-NT-119, Argonne National Laboratory, Argonne, IL (1999).

Gombert, D., S. Piet, T. Trickel, J. Carter, J.D. Vienna, and W.L. Ebert, Combined Waste Form Cost Trade Study, GNEP-SYSA-PMO-MI-DV-2009-000003, Idaho National Laboratory, Idaho Falls, ID (November 2008).

Jones, R. H. and J.T. Carter. 2013. Comparison of Waste Estimates from Recycling and Fuel Fabrication, FCRD-UFD-2013-000178, Savannah River National Laboratory, Aiken, SC.

Law, J., N. Soelberg, T. Todd, J. Tripp, C. Pereira, M. Williamson, W. Ebert, R. Jubin, B. Moyer, J. Vienna, G. Lumetta, J. Crum, T. Rudisill, J. Bresee, C. Phillips, B. Willis, P. Murray, and S. Bader, Separation and Waste Form Campaign Full Recycle Case Study, FCRD-SWF-2013-000380 (September 2013).

Law, J.D., N.R. Soelberg, T.A. Todd, G. Fredrickson, S.M. Frank, C. Pereira, M.A. Williamson, W.L. Ebert, J.L. Willit, R.T. Jubin, J.D. Vienna, G.J. Lumetta, J.V. Crum, T.S. Rudisill, J. Bresee, C. Phillips, B. Willis, and S. Bader. 2014. Separation and Waste Form Campaign Full Recycle Case Study, Revision 1, FCRD-SWF-2013-000380, Rev. 1, Idaho National Laboratory, Idaho Falls, ID.

Morrison, M.C. and K.J. Bateman. 2010. Perform 2nd Pre-Qualification CWF Test Run, FCRDSEPA-2010-000057, Idaho National Laboratory, Idaho Falls, ID.

Morrison, M.C., K.J. Bateman, and M.F. Simpson. 2010. "Scale Up of Ceramic Waste Forms for the EBR-II Spent Fuel Treatment Process," 3rd International Pyroprocess Research Conference, Research Institute of Atomic Reactors, Dimitrovgrad, Russia. 
Morrison, M.C. 2011. Memorandum, "Process Description of Activities Performed to Complete the Third Full-Scale Pre-Qualification Ceramic Waste Form Using a Blend of Eutectic LiCl-KCl Salt and Surrogate Additives," to K.J. Bateman, October 24, 2011, Idaho National Laboratory, Idaho Falls, ID.

Rudisill, T. S., S. J. Emory, D. R. Click, and D. P. DiPrete, Undissolved Solids from the Dissolution of North Anna Reactor Fuel, FCRD-SEPA-2011-000024, Savannah River National Laboratory, Aiken, SC (January 2011).

Spencer, B. B., G. D. Del Cul, R. T. Jubin, P. D. Bailey, R. S. Owens, D. W. Ramey, and E. D. Collins, Voloxidation Processing of CETE Run 2 Fuels: Experimental Results, ORNL/TM-2009/nnn (draft), Oak Ridge National Laboratory, Oak Ridge, TN (2009).

Swift, P.N. and W.M. Nutt. 2012. "Applying Insights from Repository Safety Assessments to Evaluating Impacts of Partitioning and Transmutation," in Proceedings of the 11th Actinide and Fission Product Partitioning and Transmutation, 145-154 pp. OECD, Nuclear Energy Agency.

Task Order 9: Improving the Estimates of Waste from Recycling, Sub-Task 5: Final Technical Report, Contract No.: De-NE0000291, RPT-3007827-000, AREVA Federal Services LLC, February 22, 2013.

Vienna, J.D. 2010. "Nuclear Waste Vitrification in the United States: Recent Developments and Future Options," International Journal of Applied Glass Science 1(3):309-321.

Vienna, J. D., J.V. Crum, G.J. Sevigny, and G.L. Smith, Preliminary Technology Maturation Plan for Immobilization of High-Level Waste in Glass-Ceramics, FCRD-SWF-2012-000152, PNNL-21714, Pacific Northwest National Laboratory, Richland, WA (September 2012).

Vienna, J.D., E.D. Collins, J.V. Crum, W.L. Ebert, S.M. Frank, T.G. Garn, D. Gombert, R. Jones, R.T. Jubin, V.C. Maio, J.C. Marra, J. Matyas, T.M. Nenoff, B.J. Riley, G.J. Sevigny, N.R. Soelberg, D.M. Strachan, P.K. Thallapally, and J.H. Westsik. 2015. Closed Fuel Cycle Waste Treatment Strategy, FCRD-MRWFD-2015-000674, PNNL-24114, Pacific Northwest National Laboratory, Richland, WA.

Willis, W., C. Phillips, R. Carter, S. Baker, W. Bowen, and M. Grygiel, LWR UOX and MOX Fuel Recycle and LWR MOX and Fast Reactor Fuel Fabrication Waste Estimates, Energy Solutions, Richland, WA (March 2013).

Westphal, B. R., S.M. Frank, W.M. Mccartin, D.G. Cummings, J.J. Giglio, T.P. O'holleran, P.A. Hahn, T.S. Yoo, K.C. Marsden, K.J. Bateman, and M.N. Patterson, "Characterization of Irradiated Metal Waste from the Pyrometallurgical Treatment of Used EBR-II Fuel," Metallurgical and Materials Transactions A. DOI: 10.1007/s11661-013-2114-z (2013). 